\title{
ÓLEO E EXTRATO AQUOSO DE SEMENTES DE NIM, AZADIRACTINA E ACEFATO NO CONTROLE DO PULGÃO-PRETO DO FEIJÃO-DE-CORDA ${ }^{1}$
}

\author{
José Victor Torres Alves Costa ${ }^{2}$, Ervino Bleicher ${ }^{3}$, Alex Queiroz Cysne ${ }^{3}$, Fernando Henrique Teixeira Gomes ${ }^{3}$
}

\section{ABSTRACT \\ USE OF OIL AND AQUEOUS EXTRACT OF \\ NEEM SEEDS, AZADIRACHTIN AND ACEPHATE TO CONTROL COWPEA BLACK APHID}

In this research, different trademarks and an aqueous neem seed extract were used to control the cowpea black aphid. The experimental unit consisted of a plant in a $300 \mathrm{~mL}$ disposable plastic cup, under greenhouse conditions. The following treatments were applied: 1) Absolute control (water); 2) Acephate (Orthene ${ }^{\circledR} 750 \mathrm{BR}, 1.0 \mathrm{~g}$ of the commercial product (c. p.) $\left.\left.\mathrm{L}^{-1}\right) ; 3\right) \mathrm{Natuneem}^{\circledR}\left(10 \mathrm{~mL}\right.$ c. p. $\left.\mathrm{L}^{-1}\right)$; 4) Neemazal T/S ${ }^{\circledR} 1.0 \%\left(10 \mathrm{~mL}\right.$ c. p. $\left.\mathrm{L}^{-1}\right)$; and 5) Aqueous seed extract $\left(100 \mathrm{~g} \mathrm{~L}^{-1}\right)$. Six adult apterous females were used to infest 15-days-old plants and pulverization took place 17 days after planting. Two days later, all living black aphids were counted. All azadiracthin treatments differed statistically from the control and the acephate. The seed aqueous extract was the least efficient one $(44.8 \%)$, followed by Nattuneen ${ }^{\circledR}$ $(81.15 \%)$, while Neenmazal T/S ${ }^{\circledR} 1.0 \%$ was the most efficient azadiracthin trademark $(91.35 \%)$. Azadiracthin products were efficient to control cowpea black aphid, under greenhouse conditions.

KEY-WORDS: Vigna unguiculata; Azadiracta indica; Aphis craccivora Koch; botanical insecticides; alternative control.

O feijão caupi, macaçar ou feijão-de-corda (Vigna unguiculata L. Walp) é de fundamental importância para as populações rurais nordestinas, pois, em associação com outras culturas, principalmente a do milho, possibilita a subsistência do produtor, a utilização permanente da mão de obra e uma alimentação diversificada (Cardoso 2000).

Umas das pragas da parte aérea de relevância para a cultura desta espécie de feijão é o pulgão-preto, Aphis craccivora Koch (Hemiptera: Aphididae), pois coloniza os ramos novos e folhas, sugando a seiva e

\section{RESUMO}

Avaliou-se a eficácia de diferentes formulações comerciais e extrato aquoso da semente de nim (Azadiracta indica), no controle do pulgão-preto (Aphis craccivora) em feijão-de-corda (Vigna unguiculata). A unidade experimental constou de uma planta cultivada em um copo plástico de $300 \mathrm{~mL}$, em casade-vegetação. Os tratamentos foram: 1) testemunha absoluta (água); 2) acefato (Orthene ${ }^{\circledR} 750 \mathrm{BR}, 1,0 \mathrm{~g}$ do produto comercial (p. c.) $\left.\left.\mathrm{L}^{-1}\right) ; 3\right)$ Natuneem $^{\circledR}\left(10 \mathrm{~mL}\right.$ p. c. $\left.\left.\mathrm{L}^{-1}\right) ; 4\right)$ Neenmazal $\mathrm{T} / \mathrm{S}^{\circledR}$ $1,0 \%\left(10 \mathrm{~mL}\right.$ p. c. $\left.\mathrm{L}^{-1}\right)$; e 5) Extrato aquoso da semente $\left(100 \mathrm{~g} \mathrm{~L}^{-1}\right)$. A infestação, com seis fêmeas adultas e ápteras, foi realizada 15 dias após o plantio (DAP) e a aplicação por pulverização aos 17 DAP. A avaliação foi realizada dois dias após a aplicação dos tratamentos, contando-se os pulgões vivos. Todos os compostos à base de azadiractina produziram resultados diferentes entre si e nenhum deles foi semelhante à testemunha ou ao acefato. A menor eficácia de controle $(44,8 \%)$ foi obtida pelo uso do extrato aquoso da semente, seguido do Natuneem ${ }^{\circledR}$, que apresentou eficácia de $81,15 \%$. O produto comercial Neenmazal $\mathrm{T} / \mathrm{S}^{\circledR}$ resultou na maior eficácia $(91,35 \%)$, dentre os tratamentos à base de azadiractina. Os produtos comerciais à base de azadiractina, nas concentrações utilizadas, mostraram-se eficazes no controle do pulgão-preto em feijão-de-corda, em condições de casa-de-vegetação.

PALAVRAS-CHAVE: Vigna unguiculata; Azadiracta indica; Aphis craccivora Koch; inseticidas botânicos; controle alternativo.

causando deformações nas brotações e folhas (Gallo et al. 2002). Este pulgão também injeta toxinas e transmite viroses e, por se alimentar de grande quantidade de seiva, possui, em seu aparelho digestivo, uma estrutura "câmara-filtro", que permite absorver, rapidamente, a água e os açúcares, que, posteriormente, serão expelidos na forma de mela, possibilitando a digestão de aminoácidos e nutrientes essenciais (Kristoffersen 2003). A mela serve como substrato para o desenvolvimento do fungo denominado, vulgarmente, fumagina, que prejudica os mecanismos

1. Trabalho recebido em mar./2008 e aceito para publicação em jun./2010 (nº registro: PAT 3564/ DOI: 10.5216/pat.v40i2.3564).

2. Instituto Nacional de Colonização e Reforma Agrária (INCRA), Divisão de Terras SR(27), Marabá, PA, Brasil. E-mail: jose.costa@mba.incra.gov.br.

3. Universidade Federal do Ceará, Centro de Ciências Agrárias, Departamento de Fitotecnia, Fortaleza, CE, Brasil. E-mails: ervino@ufc.br, alexcysne@gmail.com, fernandohtg@gmail.com. 
de fotossíntese e respiração, devido à cobertura de parte da superfície foliar. Como se trata de um inseto transmissor de vírus, o controle preventivo é de extrema importância (Cardoso 2000).

O pulgão-preto é, normalmente, controlado com inseticidas de síntese. O mau uso destes pode ocasionar efeito negativo ao ambiente, como, por exemplo, a mortalidade dos organismos benéficos. Como consequência, algumas culturas apresentam baixa produtividade, devido à morte de polinizadores. A mortalidade de predadores, parasitóides e entomopatógenos pode resultar na ressurgência da praga alvo, ou na elevação de um artrópode fitófago da cultura, que não tenha relevância econômica no controle da praga. O uso frequente de agroquímicos com o mesmo mecanismo de ação aumenta a pressão de seleção na população, selecionando indivíduos resistentes ao inseticida utilizado ou a outros com o mesmo modo de ação. Pode, ainda, apresentar alta toxicidade ao homem, animais domésticos e à fauna silvestre. Além disto, o uso indiscriminado destas moléculas pode contaminar riachos, rios e lagos e elevar os custos de produção. Há, portanto, a necessidade de desenvolvimento de métodos alternativos de controle, como o uso da azadiractina, substância inseticida que pode ser encontrada na árvore do nim (Azadiracta indica A. Juss).

A azadiractina é um complexo tetranortriterpenóide limonóide, presente, principalmente, nas sementes, que, devido à sua complexidade, até o momento, não foi sintetizado e todos os produtos disponíveis no mercado são preparados pela extração de compostos a partir da planta (Mordue \& Nisbet 2000, Martinez 2002).

Neste contexto, objetivou-se, nesta pesquisa, avaliar o efeito do óleo e extrato aquoso de sementes de nim, azadiractina e do inseticida fosforado acefato sobre o pulgão-preto, em feijão-de-corda.

O experimento foi conduzido em casa-devegetação, coberta com plástico de 200 micras UV, na Universidade Federal do Ceará, Campus do Pici, em Fortaleza (CE). Duas sementes de V. unguiculata foram plantadas em cada copo plástico de $300 \mathrm{~mL}$ de capacidade, com substrato composto de 50\% de solo, $30 \%$ de húmus de minhoca, $10 \%$ de vermiculita expandida e $10 \%$ de substrato comercial Plantmax ${ }^{\circledR}$. O desbaste foi efetuado sete dias após o plantio (DAP), deixando-se uma planta por copo. A unidade experimental foi constituída pela planta no copo, utilizando-se, no estudo, oito repetições, em delineamento inteiramente casualizado.
A infestação, com seis fêmeas adultas e ápteras, selecionadas pela codícula bem visível, coloração escura brilhante e formato arredondado, foi realizada, em cada planta, aos 15 DAP.

Os tratamentos aplicados consistiram de: 1) testemunha absoluta (água); 2) acefato (Orthene ${ }^{\circledR}$ 750 BR) (inseticida de referência), na dosagem de $1,0 \mathrm{~g}$ do produto comercial (p. c.) por litro de água; 3) Natuneem ${ }^{\circledR}$ (óleo das sementes de nim extraído a frio) a $10 \mathrm{~mL}$ p. c. $\mathrm{L}^{-1}$; 4) Neenmazal T/S ${ }^{\circledR} 1,0 \%$ de azadiractina (ingrediente ativo purificado do endosperma das sementes de nim), a $10 \mathrm{~mL}$ p. c. $\mathrm{L}^{-1}$; e 5) Extrato aquoso da semente $\left(100 \mathrm{~g} \mathrm{~L}^{-1}\right)$. O extrato aquoso foi obtido adicionando-se $100 \mathrm{~g}$ da semente moída (em liquidificador) por litro de água, o tempo de extração foi de 24 horas e, após a filtragem, foi realizada a aplicação. As sementes originaram-se de plantio efetuado na Embrapa Agroindústria Tropical, em Fortaleza (CE).

A aplicação por pulverização foi realizada pela manhã, sobre as ninfas nascidas, aos 17 DAP, após a retirada das fêmeas adultas e ápteras (para evitar a reinfestação), sendo utilizado um compressor a ar e uma pistola de pressão tipo aerógrafo $\left(\operatorname{Arprex}^{\circledR}\right.$ modelo-5), com um bico de $0,8 \mathrm{~mm}$ e pressão de trabalho de $20-30 \mathrm{lbs}^{\text {-pol2 }}$. A pulverização foi efetuada em cobertura total, até o ponto próximo ao escorrimento.

A avaliação foi realizada dois dias após a aplicação dos tratamentos, contando-se os pulgões vivos. A partir da obtenção do número de pulgões vivos, foi efetuada análise de variância, sendo as médias comparadas pelo teste de Duncan, a 5\% de significância. Para análise, os dados foram transformados por $\sqrt{x+0,5}$. A eficiência foi calculada utilizando-se a fórmula de Abbott (1925).

Os dados relativos à testemunha contendo água e o inseticida de referência acefato $750 \mathrm{BR}$, usado como testemunha relativa, evidenciam que a metodologia empregada foi adequada. Assim sendo, todos os tratamentos contendo produtos potencialmente tóxicos aos insetos diferiram entre si e nenhum deles foi semelhante à testemunha ou ao inseticida de referência acefato 750 BR (Tabela 1).

A menor eficiência (44,8\%) foi obtida pelo uso do extrato aquoso da semente. Esta baixa eficiência pode ter ocorrido devido ao fato de que, além dos compostos ativos, a semente apresenta outros componentes inertes presentes na casca (tegumento) e no endosperma. Além disto, Martinez (2002) destaca a 
Tabela 1. Número médio de ninfas vivas e eficiência de formulações comerciais e extrato de semente de nim (Azadiracta indica A. Juss) sobre o pulgãopreto (Aphis craccivora Koch), em feijão-de-corda (Vigna unguiculata L. Walp), em casa-de-vegetação (Fortaleza, CE, 2005).

\begin{tabular}{|c|c|c|c|}
\hline Tratamentos & Dose & Ninfas $^{1}$ & Eficiência $(\%)^{2}$ \\
\hline Testemunha & - & $65,00 \mathrm{a}$ & - \\
\hline Extrato aquoso da semente & $100 \mathrm{~g} \mathrm{~L}^{-1}$ & $35,87 \mathrm{~b}$ & 44,80 \\
\hline Natuneem $^{\circledR}$ & $10 \mathrm{~mL}$ p. c. $\mathrm{L}^{-1}$ & $12,25 \mathrm{c}$ & 81,15 \\
\hline Neenmazal T/S ${ }^{\circledR} 1,0 \%$ AZA & $10 \mathrm{~mL}$ p. c. $\mathrm{L}^{-1}$ & $5,62 \mathrm{~d}$ & 91,35 \\
\hline Acefato (Orthene $\left.{ }^{\circledR} 750 \mathrm{BR}\right)$ & 1 g p.c. $\mathrm{L}^{-1}$ & $0,00 \mathrm{e}$ & 100,00 \\
\hline CV (\%) & - & 17,25 & - \\
\hline
\end{tabular}

${ }^{1}$ Médias não seguidas da mesma letra diferem, estatisticamente, entre si, a 5\% de probabilidade de erro, pelo teste de Duncan.

${ }^{2}$ Calculada pela fórmula de Abbott (1925)

grande variação no teor de azadiractina nas sementes, sendo que os fatores responsáveis por tais variações ainda não são bem claros. Sabe-se que estes teores variam de 2,32 mg a 6,10 mg, por grama de semente, de acordo com a origem do material e análises efetuadas por autores de vários países. Os resultados com extrato de semente, aqui obtidos, tiveram eficácia semelhante aos encontrados por Gonçalves (2004), diferindo da testemunha e do inseticida de referência, em condições de casa-de-vegetação, para o mesmo inseto. No entanto, este autor utilizou $8 \mathrm{~g}$ da semente moída por $100 \mathrm{~mL}$, realizou a infestação com menor número de insetos e a aplicação foi feita em períodos diferentes ao deste trabalho. Ulrichs et al. (2001) não obtiveram sucesso na utilização do extrato da semente a $2 \%$, sobre $A$. craccivora, em condições de campo. Nestas condições, além da variabilidade da fonte de azadiractina apontada por Martinez (2002), há a fotodegradação, comum aos inseticidas botânicos.

O óleo extraído da semente, comercializado como Natuneem $^{\circledR}$, que não passa por processo de purificação, apresentou eficácia de $81,15 \%$, quase duas vezes superior à do extrato de semente. Como este produto tem por base o óleo da semente, há, na sua composição, outros compostos, dentre os quais se destacam a salanina, 14-epoxiazadiradiona, meliantrol, melianona, gedunina, nimbolina, nimbina, nimbinem, deacetilsalanina, azadiractol, azadirona, vilosinina e meliacarpina, cujas bioatividades não são totalmente conhecidas. Acredita-se que a mortalidade possa ser atribuída, principalmente, à azadiractina (Jones et al. 1989, Lee et al. 1991, Kraus 1995). Cabe ressaltar que substâncias oleosas são passíveis de causar mortalidade por asfixia a insetos, devido ao entupimento dos espiráculos.
A maior eficiência (91,35\%) foi obtida quando se utilizou o Neenmazal $\mathrm{T} / \mathrm{S}^{\circledR} 1,0 \%$, possivelmente pelo fato de este produto sofrer processo de purificação, concentrando a azadiractina e eliminando os produtos inertes ou pouco ativos. $\mathrm{O}$ fabricante do produto Natuneem ${ }^{\circledR}$ não informa o teor de princípio ativo, mas, mesmo assim, pode-se notar que a sua eficiência é inferior à do Neenmazal T/S $\mathrm{S}^{\circledR} 1,0 \%$, sobre o pulgão. Ulrichs et al. (2001), em condições de campo, e Gonçalves (2004), em casa-de-vegetação, utilizando o Neenmazal $\mathrm{T} / \mathrm{S}^{\circledR}$ a $1,0 \%$ e $1,2 \%$, respectivamente, relatam resultados semelhantes aos desta pesquisa.

Apesar da baixa eficiência do extrato das sementes, a sua utilização não pode ser descartada. São necessários novos estudos, testando a frequência de aplicação e uma maior concentração, para tentar potencializar seus efeitos, e, assim, recomendar sua possível utilização em pequenas áreas. Além disto, nem todos os modos de ação foram quantificados, já que alguns necessitam de maior período para a sua detecção. Martinez (2002) relata que a azadiractina possui ação por ingestão significativamente superior à de contato e que os derivados do nim possuem, ainda, efeito antialimentar, regulador do crescimento, além de alterarem o comportamento, podendo causar anomalias fisiológicas.

Gonçalves (2004), utilizando o Neemazal ${ }^{\circledR}$ $1,2 \%$ e o extrato aquoso da semente, aplicado via sistema radicular, obteve redução significativa na média de pulgões $A$. craccivora nascidos, bem como comprovada influência na reprodução de insetos. Outras três espécies de pulgões, quando tratadas via pulverização com óleo de nim, azadiractina e a formulação comercial Margozan-O (3\% de AZA), tiveram redução na fecundidade e inibição da reprodução (Stark \& Rangus 1994, Lowery \& Isman 1996). Além destes efeitos, a grande quantidade de componentes ativos contidos no óleo das sementes dificulta a indução de resistência aos insetos (Martinez 2002).

Não foi observada fitotoxicidade na concentração de $1 \%$ dos óleos emulsionáveis e na dose de $10 \%$ do extrato da semente utilizada, apesar de os relatos de Srivastava \& Parmar (1985) indicarem que soluções de óleo emulsionável a partir de $1 \%$ causam tais complicações na cultura do sorgo (Sorghum bicolor L. Moench). No feijão, Jakob (1992) constatou tais problemas somente a partir de $2 \%$. Quanto à utilização dos extratos aquosos da semente, Martinez (2002) afirma que, utilizando-se $50 \mathrm{~g} \mathrm{~L}^{-1}$ ou $5 \%$, os danos 
não são considerados significativos. Assim sendo, existe uma margem de segurança entre o aplicado neste experimento e o relatado na bibliografia.

O óleo de sementes de nim e azadiractina foram eficazes no controle de Aphis craccivora. O extrato aquoso das sementes, embora eficiente, não pode ser considerado eficaz, na forma de aplicação utilizada nesta pesquisa.

\section{AGRADECIMENTOS}

À Secretaria de Educação Superior do Ministério da Educação e Cultura (MEC-Sesu), pela bolsa de estudo concedida aos autores, através do Programa de Educação Tutorial (PET).

\section{REFERÊNCIAS}

ABBOTT, W. S. A method of computing the effectiveness of an insecticide. Journal of Economic Entomology, Marson, v. 18, n. 1, p. 265-267, 1925.

CARDOSO, M. J. A cultura do caupi no Meio-Norte do Brasil. Teresina: Embrapa Meio-Norte, 2000.

GALLO, D. et al. Entomologia agrícola. Piracicaba: Fealq, 2002.

GONÇALVES, M. E. C. Atividade de derivados de nim aplicados por pulverização e via sistema radicular sobre a mosca-branca em meloeiro e o pulgão-preto em feijão-de-corda. Tese (Doutorado em Fitotecnia)-Centro de Ciências Agrárias, Universidade Federal do Ceará, Fortaleza, 2004.

JAKOB, G. Studies on the phytotoxicity of different neem seed extracts. In: WORKSHOP ON PRACTICE ORIENTED RESULTS ON USEAND PRODUCTION OF NEEM-INGREDIENTS, 1., 1992, Wetzlar. Proceedings... Giessen: Druck \& Graphic, 1992. p. 95-96.

JONES, P. S. et al. The chemistry of the neem tree. In: JACOBSON, M. (Ed.). Focus on phytochemical pesticides: the neem tree. Boca Raton: CRC, 1989. p. 47-67.
KRAUS, W. Biologically active ingredients. In: SCHMUTTERER, H. (Ed.). The neem tree: source of unique natural products for integrated pest management, medicine, industry and other purposes. Weinheim: VCH, 1995. p. 35-88.

KRISTOFFERSEN, L. The chemical ecology of Homoptera: from host plants to conspecific interactions. Lund: Lund University, 2003. (Introductory paper, n. 147).

LEE, S. M. et al. Insecticidal constituents of Azadirachta indica and Melia azedarach (Meliaceae). American Chemical Society Symposium Series, Washington, v. 449, n. 1, p. 293-304, 1991.

LOWERY, D. T.; ISMAN, M. B. Inhibition of aphid (Homoptera: Aphididae) reproduction by neem seed oil and azadirachtin. Journal of Economic Entomology, Marson, v. 89, n. 3, p. 602-607, 1996.

MARTINEZ, S. S. O nim - Azadiracta indica: natureza, usos múltiplos, produção. Londrina: Iapar, 2002.

MORDUE, A. J.; NISBET, A. J. Azadirachtin from the neem tree Azadirachta indica: its actions against insects. Anais da Sociedade Entomológica do Brasil, Londrina, v. 29, n. 4 , p. $615-632,2000$

SRIVASTAVA, K. D.; PARMAR, B. S. Evaluation of neem oil emulsifiable concentrate against sorghum aphids. Neem Newsletter, Washington, v. 2, n. 1, p. 7, 1985.

STARK, J. D.; RANGUS, T. M. Lethal and sublethal effects of neem insecticide formulation 'Margosan-O', on the pea aphid. Pesticides Science, London, v. 41, n. 1, p. 155-160, 1994.

ULRICHS, C. H.; MEWIS, I.; SCHNITZLER, W. H. Efficacy of neem and diatomaceous earth against cowpea aphids and their deleterious effect on predating coccinelidae. Journal of Applied Entomology, London, v. 125, n. 9-10, p. 571-575, 2001. 